\title{
The use of phytoplankton pigments for identifying and quantifying phytoplankton groups in coastal areas: testing the influence of light and nutrients on pigment/chlorophyll a ratios
}

\author{
L. Schlüter ${ }^{1, *}$, F. Møhlenberg ${ }^{1}$, H. Havskum ${ }^{1}$, S. Larsen ${ }^{2}$ \\ ${ }^{1}$ The International Agency for ${ }^{14} \mathrm{C}$ Determination, VKI, Agern Allé 11, 2970 Horsholm, Denmark \\ ${ }^{2}$ County of Funen, Ørbakvej 100, 5220 Odense Sø, Denmark
}

\begin{abstract}
The influences of light and nutrients on ratios of pigments/chlorophyll a (chl a) were investigated for several species of different phytoplankton groups from estuaries and coastal areas for the purpose of calculating the biomass of individual phytoplankton groups as chl a based on pigment/chl a ratios. Pigment ratios were constructed for varying light intensities and qualities and for nutrient-starved algae cultured in the laboratory. The pigment ratios were tested on 4 data sets obtained in estuaries and coastal areas using the CHEMTAX program, for calculating phytoplankton group abundance as chl a. Field samples were collected over a variety of time and spatial scales as well as being subjects to variations in light and nutrient conditions. The pigment/chl a ratios derived from the different treatments in culture experiments generally had a minor effect on the CHEMTAX biomass calculations, although the biomass of cyanobacteria and prymnesiophytes was significantly influenced by the ratios chosen. In addition, interspecies variations in pigment/chl a ratios within the individual phytoplankton groups were even more pronounced than variations caused by the different growth conditions, indicating that the ratios chosen for CHEMTAX calculations should, if at all possible. reflect the dominant phytoplankton species present in a given area. For 2 of the data sets, where larger algal cells dominated, the composition and the biomass of the individual phytoplankton groups, using our pigment ratios in the CHEMTAX program, corresponded well to microscopic determinations of the biomass of phytoplankton. One of the data sets, where small algal cells dominated, was counted under the microscope by 2 different laboratories. Their biomass estimates were not consistent, and both disagreed with the CHEMTAX results. This probably reflects the subjectivity of microscopic analysis, which is greatest when small phytoplankton cells dominate. In a fourth data set, owing to the high sensitivity and reproducibility of the pigment analysis, differences were detected between phytoplankton. groups over a transect of $5 \mathrm{~km}$, which might have been unresolved using standard microscopic techniques.
\end{abstract}

KEY WORDS: Phytoplankton - Chlorophyll a $\cdot$ Pigments $\cdot$ HPLC $\cdot$ CHEMTAX

\section{INTRODUCTION}

In the past, the composition and abundance of phytoplankton populations have been determined by microscopy. Since microscopic enumerations are complicated and time consuming, the number of samples and algal cells that can be counted is limited, and the coef-

•E-mail: 1sc@vki.dk ficient of variation of cells counted under the microscope is high, i.e. between 15 and $50 \%$ (Wilhelm et al. 1991). Minor variations in the composition of phytoplankton are consequently not revealed when using microscopy technique.

The introduction of pigment analyses by High Pressure Liquid Chromatography (HPLC) (Abaychi \& Riley 1979, Mantoura \& Llewellyn 1983) facilitated easy and accurate separation, identification, and 
quantification of phytoplankton pigments. The characteristic composition of phytoplankton pigments within the individual phytoplankton groups and the occurrence of diagnostic pigments has favored the use of pigment analysis in investigations of the composition of phytoplankton populations (e.g. Gieskes \& Kraay 1983, Bidigare et al. 1990, Althuis et al. 1994). In contrast to microscopic enumerations, analysis by HPLC is reproducible (i.e. the coefficient of variation on repeated injections is usually below $1 \%$ : L. Schlüter unpubl. results), and the method provides a rapid way to examine the phytoplankton group composition: with an autosampler connected to the HPLC. more than 40 samples can be analysed per day. The large number of samples that can be processed by HPLC allows a more thorough examination of the structure and dynamics of phytoplankton populations than has been possible using enumeration of phytoplankton under the microscope.

The HPLC method has proven especially useful for samples from oligotrophic areas (e.g. Letelier et al. 1993, Peeken 1997), where the smallest algal cells can only be correctly identified by electron microscopy (Andersen et al. 1996). It has been used more sparsely for samples from eutrophic, coastal marine areas (e.g Bianchi et al. 1997), although the HPLC should be useful for detecting phytoplankton groups in such areas too. In the beginning, conclusions using pigment data obtained by HPLC analysis were mostly qualitative (e.g. Gieskes \& Kraay 1986, Bidigare et al. 1990), but recent work indicates that the pigments can also be used as quantitative measures of phytoplankton groups (Schlüter \& Havskum 1997). To estimate the biomass of phytoplankton groups from the pigment concentrations, Gieskes et al. (1988) used multiple linear regression to quantify the contribution of the individual phytoplankton groups to the total concentration of chlorophyll a (chl a). As discussed in Mackey et al. (1996) and Schlüter \& Havskum (1997), the use of linear regression in this way assumes that the ratios between the individual diagnostic pigments and chl a are constant. If the ratios change (e.g. owing to light adaptation), this approach cannot be used. Other methods (e.g. Everitt et al. 1990, Letelier et al. 1993, Goericke \& Montoya 1998) have been applied to determine the abundance of the individual phytoplankton groups from the concentration of the marker pigments. Mackey et al. (1996) introduced the CHEMTAX program, in which factor analycis and steepest decent algorithm are used to find the best fit to the data based on suggested pigment/chl a ratios of both diagnostic pigments and pigments present in several phytoplankton groups for the phytoplankton groups to be determined. Mackey et al. $(1996,1998)$ and Wright et al. (1996) provided stiong evidence that CHEMTAX suc- cessfully calculates phytoplankton group abundance in terms of their chl a concentration from pigment concentrations in ocean samples, even when there were phytoplankton groups without diagnostic pigments or when the initial suggested pigment ratios contained large errors. More data should of course be tested, but CHEMTAX certainly seems a promising method for determination of the abundance and composition of phytoplankton groups.

The application of the CHEMTAX program to coastal and estuary samples is limited by the lack of known pigment ratios for different areas (Wright et al. 1996). The pigment ratios available (i.e. Table 1 in Mackey et al. 1996), are derived from 18 different references. For most phytoplankton groups, the ratios in the references vary with growth conditions in the cultures. Since concentrations of carotenoids and chl $a$ in the cells are influenced by irradiance and nutrient limitation (Latasa 1995, Goericke \& Montoya 1998), providing appropriate growth conditions in culture experiments is critical for the assignment of valid pigment/ chl a ratios. Extensive knowledge of the influence of light intensity, light quality, and nutrient limitation on the pigment/chl a ratios of different phytoplankton species is certainly needed before the CHEMTAX program can be generally applied.

In the work presented here, algal cultures were used to elucidate the influence of varying light climate and nutrient limitation on the ratios of pigments to chl a. The algal species chosen were mainly species that are prevalent in estuaries and coastal areas. The pigment ratios generated were then tested using the CHEMTAX program on 4 different data sets derived from different coastal areas, which included sampling over various temporal and spatial scales, and variations in light and nutrient conditions. The results were compared with microscopic determinations of phytoplankton biomass for 3 of the data sets. Furthermore, the reproducibility of microscopic enumerations was evaluated by having 2 different laboratories count the same samples under the microscope and estimate the biomass of the phytoplankton groups by standard methods.

\section{MATERIALS AND METHODS}

Culture experiments. The algal species selected for the experiments were the dinoflagellates Peridinium faeroense Paulsen (Scandinavian Culture Collection (SCCAP), K-500), and Prorocentium micans Ehrenberg (SCCAP, K-0335), and the diatoms PhaeodactyIum tricornutum Bohlin (Marine Biological Laboratory [MiBL], Helsingor, Denmark) and Ditylum brightwellii (West) Grunow (MBL). Of the prymnesiophytes, 3 out 
Table 1. Average light intensity, reaching the incubation bags at the different depths, in the Oosterschelde, June 1996

\begin{tabular}{|c|c|c|c|c|c|c|c|}
\hline $\begin{array}{l}\text { Depth above } \\
\text { the bottom }(\mathrm{m})\end{array}$ & June: $17-18$ & $18-19$ & $\begin{array}{l}21-22 \\
(\mu \mathrm{mol} p\end{array}$ & $\begin{array}{l}22-23 \\
\text { hotons }\end{array}$ & $\begin{array}{l}24-25 \\
\left.m^{-1} s^{-1}\right)\end{array}$ & $25-26$ & $27-28$ \\
\hline 1 & 43 & 12 & 13 & 16 & 11 & 26 & 11 \\
\hline 2 & 69 & 25 & 27 & 31 & 21 & 53 & 23 \\
\hline 3 & 111 & 54 & 57 & 63 & 42 & 106 & 49 \\
\hline 4 & 228 & 115 & 120 & 127 & 83 & 213 & 104 \\
\hline 5 & 369 & 246 & 251 & 256 & 165 & 429 & 223 \\
\hline
\end{tabular}

prevalent in oligotrophic and coastal environments, respectively, by screening the cultures with blue and green filters. The absorption properties of the 2 types of filters resembled the oceanic Type III (blue), and the coastal Type 9 (green) in Jerlov (1968), and the resulting irradiance reaching the 2 screened cultures was $88 \mu \mathrm{mol}$ photons $\mathrm{m}^{-2} \mathrm{~s}^{-1}$ for the BL cultures and 98 umol photons $\mathrm{m}^{-2} \mathrm{~s}^{-1}$ for the GL cultures, measured with the $2 \pi$ quantum of the 4 types defined by Jeffrey \& Wright (1994) were chosen: Type 1 (without 19'-hexanoyloxyfucoxanthin [19'-hex]): Isochrysis galbana Parke (MBL); Type 3 (with 19'-hex): Emiliania huxleyi (Lohman) (isolated from Oslo Fjord, 1990); and Type 4 (with 19'-hex and 19'-butanoyloxyfucoxanthin [19'-but]): Phaeocystis sp. Lagerheim (SCCAP, K-0494). Other species used were the chrysophyte Apedinella radians (Lohmann) Campbell (SCCAP, K-0077), the pelagophyte Pelagococcus subviridis (Plymouth Culture Collection, C-599), the cryptophytes Rhodomonas salina (Wislouch) Hill et Wetherbee (MBL) and Plagioselmis prolonga Butcher (SCCAP, K-0429), the cyanobacterium Synechococcus sp. (Nägeli) (provided by Dr W. Eikrem, Marine Botany, University of Oslo, Norway), the chlorophytes Chlorella sp. (provided by Dr L. Shapiro, Oregon Marine Biology Institute, Charleston, USA) and Brachiomonas submarina Ettl (SCCAP, K-0437), the prasinophytes Pycnococcus provasolii Guillard (SCCAP, K-0249) and Pyramimonas disomata Butcher (SCCAP, K-0285), and the euglenophyte Eutreptiella gymnastica Throndsen (SCCAP, K-0333).

The algal cultures were grown on a 16:8 h light:dark cycle at $17^{\circ} \mathrm{C}$ in Keller medium, 30\% (Keller et al. 1987), in 11 glass bottles, and were bubbled with filtered air. Non-motile algae were stirred gently with a magnetic stirrer to keep the cells suspended. The cultures were grown at 3 different light intensities, using Pope fluorescent tubes (36W/33): 'low light' (LL), 'medium light' (ML), and 'high light' (HL). HL cultures received light from 2 sides, ML from 1 side, while LL cultures received only scattered light. The irradiances reaching the cultures, measured with a Li-Cor Li 1000 meter with both $4 \pi$ and $2 \pi$ quantum sensors, in $\mu \mathrm{mol}$ photons $\mathrm{m}^{-2} \mathrm{~s}^{-1}$, were LL: $23(4 \pi) / 4(2 \pi), \mathrm{ML}: 230(4 \pi) / 94$ $(2 \pi)$ and HL: $554(4 \pi) / 269$ from one side and 118 from the other side $(2 \pi)$. Since the cultures were allowed to become dense (chl a concentrations were between 50 and $500 \mu \mathrm{g} \mathrm{l}^{-1}$ ), producing self shading, the light intensities reaching individual algal cells were lower than the incident irradiances.

The cultures were also grown at 2 different light qualities: blue (BL) and green light (GL), which are sensor. The screened cultures were ventilated with a fan, which ensured that the temperature was kept at $17^{\circ} \mathrm{C}$.

The algae were maintained as semi-continuous batch cultures by counting the cells in each light treatment in a haemocytometer every day, calculating the growth rates to ensure that the algal celis were growing exponentially (usually more than 1 cell division $\mathrm{d}^{-1}$ in $\mathrm{ML}$ and $\mathrm{HL}$ treatments), and replacing part of the algal culture with fresh medium to reach the initial cell density. The cultures were grown for at least 4 or $5 \mathrm{~d}$ to ensure that the cells were acclimated to the given light conditions. Cells were harvested at noon by filtering replicate sub-samples through GF/F filters. The filters were quickly wrapped in aluminium foil, and immediately frozen in liquid nitrogen. Each filtration and freezing step was finished within 1 min after the cultures were removed from the light source. The filters were stored in liquid nitrogen until analysis by HPLC, usually within $2 \mathrm{wk}$. After these subsamplings, the ML cultures were allowed to grow without dilution, until cell division terminated (stationary growth [SG]), usually within $4 \mathrm{~d}$. Subsamples were then filtered as described above.

Field experiments. Pigment analyses and microscopic enumerations were performed on samples collected from 3 different coastal areas: the Dutch estuary Oosterschelde $\left(51^{\circ} 30^{\prime} \mathrm{N}, 4^{\circ} \mathrm{E}\right)$, the Norwegian Hylsfjord $\left(59^{\circ} 30^{\prime} \mathrm{N}, 6^{\circ} 30^{\prime} \mathrm{E}\right)$, the Danish Great Belt $\left(55^{\circ} 15^{\prime} \mathrm{N}, 11^{\circ} \mathrm{E}\right)$, and pigment analyses alone were performed on samples from the Danish/Swedish Øresund $\left(55^{\circ} 30^{\prime} \mathrm{N}, 12^{\circ} 45^{\prime} \mathrm{E}\right)$.

The Oosterschelde: Surface water was collected before and after tidal water had passed over an extensive mussel bed of Mytilus edulis L. The 2 samples were incubated for $24 \mathrm{~h}$ in $10 \mathrm{l}$ polyethylene bags on 7 occasions over $2 \mathrm{wk}$ in June 1996. The bags were deployed at $1 \mathrm{~m}$ intervals vertically above the bottom at a station located beside the mussel bed. The tidal amplitude averages $3 \mathrm{~m}$ in the Oosterschelde, resulting in profound variations in incubation depths. The light reaching the bags in each $24 \mathrm{~h}$ period was calculated from the incident radiation, the light attenuation 
Table 2. Pigment/chlorophyll a ratios in (a) dinoflagellates, diatoms, prymnesiophytes, a pedinellophyte, a pelagophyte, cryptophytes and (b) a cyanobacteria, chlorophytes, prasinophytes, and an euglenophyte for each pigment detected in the different light treatments as averages of 2 replicates (left column) and as the average of the 3 light intensity studies (right column). 19'-but-fuco: 19'-butanoyloxyfucoxanthin, 19'-hex-fuco: 19'-hexanoyloxyfucoxanthin, LL: low light, ML. medium light, HL: high light, GL: green light, BL: blue light, SG: stationary growth (see text for details), nd: not determined

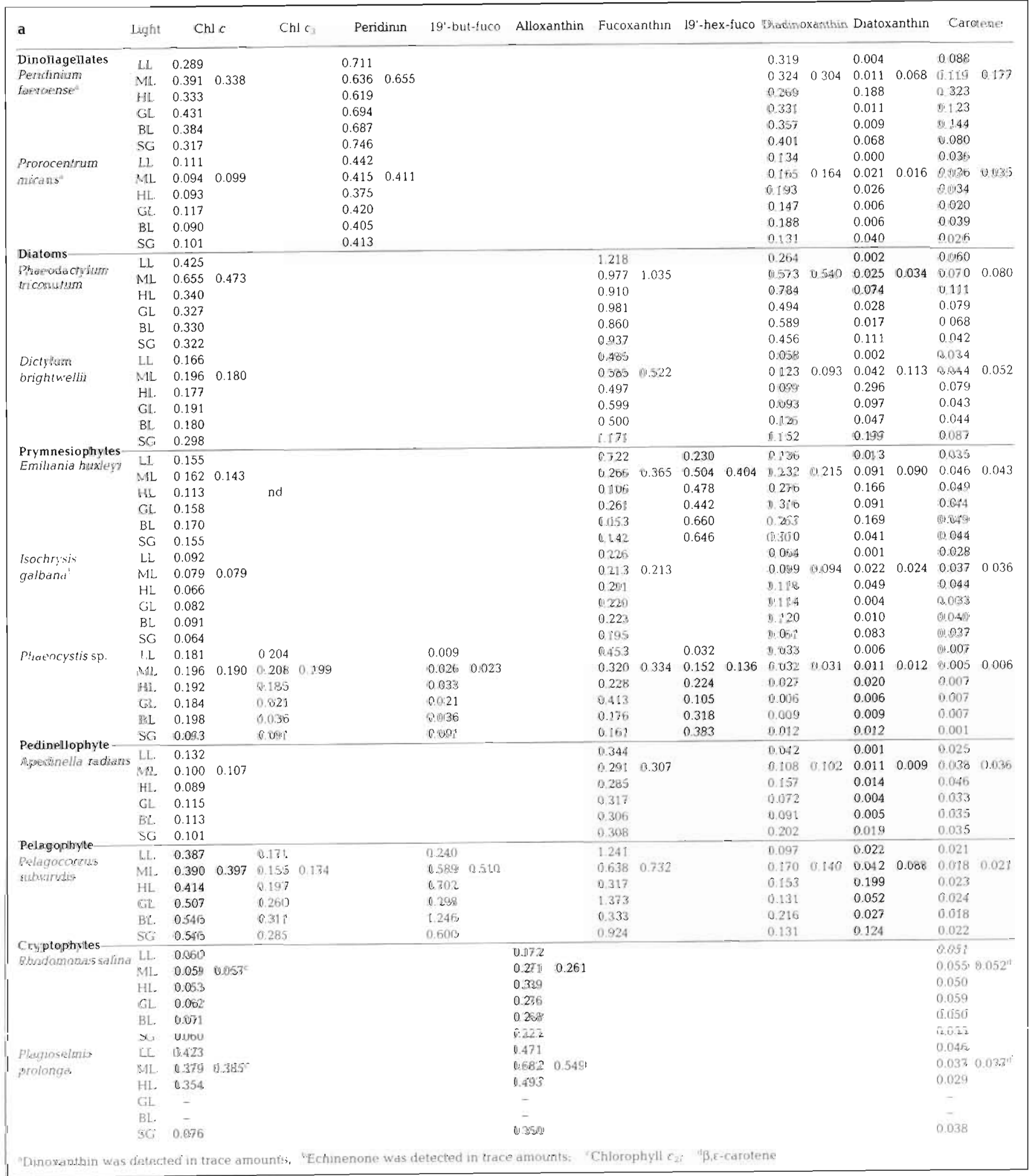


coefficient, and a varying depth (cos function), as described by Mohlenberg (unpubl.) (Table 1). Prior to and after incubation, samples were transported to a laboratory nearby, filtered onto GF/F filters within $1 \mathrm{~h}$, and immediately frozen in liquid nitrogen. The pigments were analysed by HPLC within 3 mo according to the methods described below. For microscopic determination of phytoplankton, samples for determination of larger algae ( $>20 \mu \mathrm{m})$ were fixed in Lugol's solution and enumerated using an inverted microscope as described below. Samples for determination of pico and nano algae were fixed in glutaraldehyde, filtered onto black $0.8 \mu \mathrm{m}$ filters, and enumerated using an epifluorescence microscope as described below.

The Hylsfjord: A mesocosm study was conducted in July 1995. Four enclosures, each containing 1600 l, were treated with nutrients by adding either nitrogen $(N)$, nitrogen and phosphorus (NP), nitrogen and glycine (NG), or nitrogen, phosphorus and glycine (NPG) to the enclosures. Nutrients were added daily as follows: $157 \mu \mathrm{mol} \mathrm{KH}_{2} \mathrm{PO}_{4}, 3140 \mu \mathrm{mol} \mathrm{NaNO}_{3}$, and $6280 \mu \mathrm{mol}$ glycine. Since phytoplankton in the Hylsfjord is apparently phosphorus limited (Aure \& Rey
1992. Thingstad et al. 1993), the $\mathrm{N}$ enclosure constituted a control. Further details about sampling and experimental setup are described in Thingstad et al. (1999). Samples were taken every day during a period of $9 \mathrm{~d}$ at 3 depths, which were pooled into 1 sample before sampling for microscopic enumeration and pigment analysis. The samples were only counted under the microscope every second day, although an extra sample was counted for each enclosure on the second experimental day. Some of the results from the Hylsfjord have been presented elsewhere (Havskum \& Hansen 1997, Schlüter \& Havskum 1997). In the present study, pigment ratios, derived from the laboratory experiments described above, were used in the CHEMTAX program (Mackey et al. 1996) to calculate the chl a biomass of the phytoplankton groups from the measured pigment concentrations. These results were compared to the biomass of the phytoplankton groups found under the microscope.

The Great Belt: Water samples were taken from the water surface every second week during a period of $3 \frac{1}{2}$ mo from June to September 1997. The samples were counted microscopically by 2 laboratories, $a$ and $b$.

Table 2 (continued)

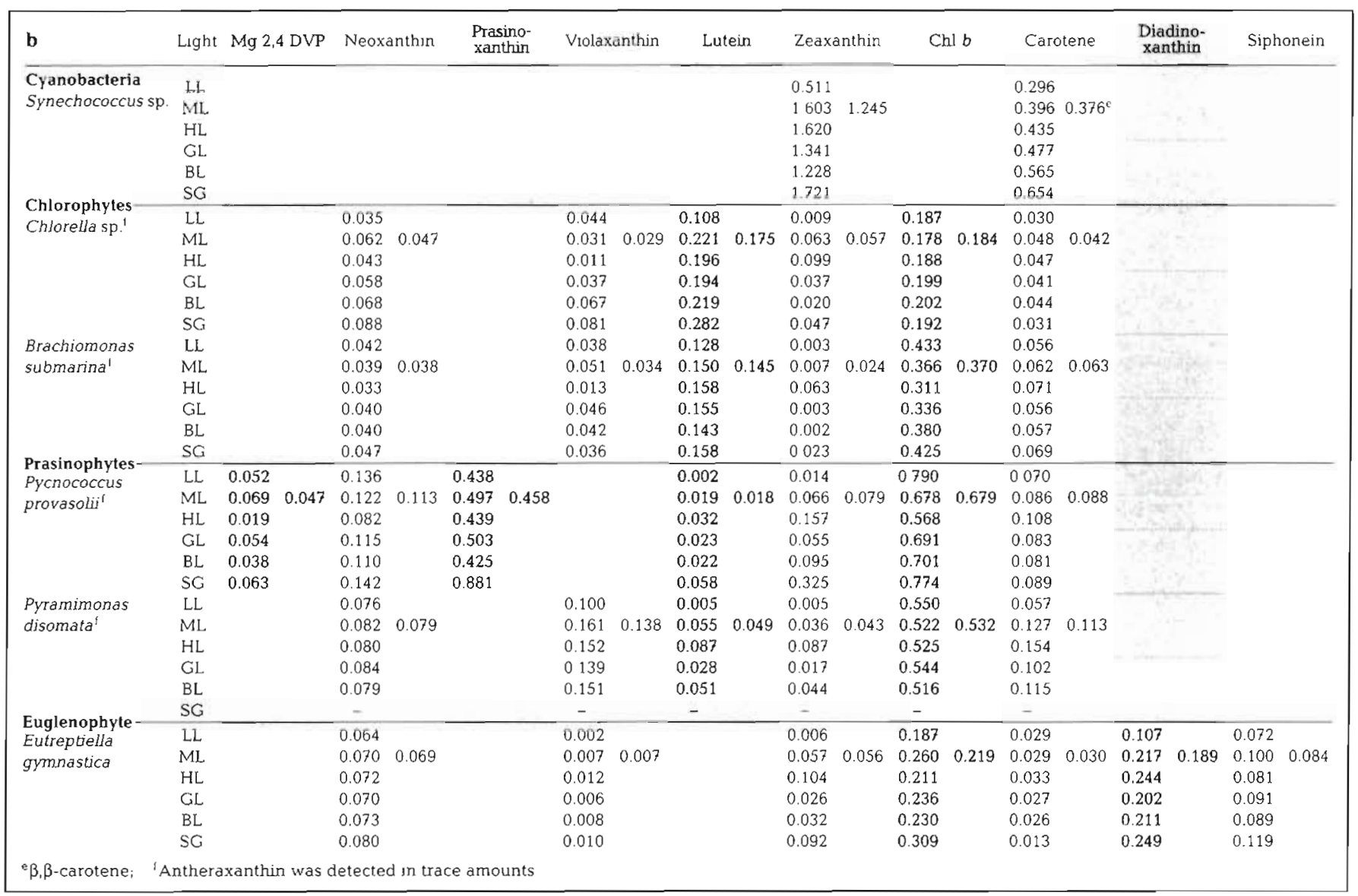


Laboratory a counted only samples fixed in Lugol's solution under an ordinary light microscope, while Laboratory $b$ analysed the samples by both ordinary light and epifluorescence microscopy as described below.

Oresund: Water was sampled on 10 June 1997 at 2 depths: at the surface and $0.5 \mathrm{~m}$ above $1 / 2$ secchi depth on both sides of a sediment plume, which had arisen as a consequence of a spill from a dredger The stations were placed in pairs, 8 stations in all, on both sides of the sediment plume along a $5 \mathrm{~km}$ horizontal line following the sediment plume.

HPLC analysis. The filters were thawed, placed wet in $3 \mathrm{ml} \mathrm{100 \%}$ acetone, resulting in a nominal concentration of $90 \%$ acetone (Bidigare 1991), sonicated on ice for $10 \mathrm{~min}$, and extracted for $24 \mathrm{~h}$ at $4^{\circ} \mathrm{C}$. The filters and cell debris were filtered from the extract using disposable syringes and $0.2 \mu \mathrm{m}$ Teflon syringe filters. $1 \mathrm{ml}$ extract and $0.3 \mathrm{ml}$ water (HPLC-grade) were transferred to HPLC vials and the vials were placed in the cooling rack of the HPLC. The samples were injected into a Shimadzu LC-10A HPLC system according to the method described by Wright et al. (1991), although the linear gradient was modified slightly 0 min: $100 \%$ A; 2 min: $100 \% \mathrm{~B}_{i} 2.6$ min: $90 \% \mathrm{~B} / 10 \% \mathrm{C} ; 13.6 \mathrm{~min}$; $65 \% \mathrm{~B} / 35 \% \mathrm{C}_{i} 20 \mathrm{~min}: 31 \% \mathrm{~B} / 69 \% \mathrm{C} ; 28 \mathrm{~min}: 100 \%$ B; 31 min: $100 \%$ A. Divinyl chls a and $b$ could not be separated from monovinyl chls $a$ and $b$ with this method, but since the investigation areas were all brackish coastal areas, prochlorophytes were not likely to be present. The HPLC system was calibrated with pigment standards from The International Agency for ${ }^{14} \mathrm{C}$ Determination, VKI, Hørsholm, Denmark. Peak identities were routinely confirmed by on-line diode array

Microscopic enumerations. The phytoplankton cells were assigned to groups by epifluorescence and ordinary light microscopy, and at least 100 cells were enumerated. For each sample, at least 20 cells in each group were measured. The cell volume was calculated by assigning simple geometric shapes to the organisms of which 1 or 2 dimensions were measured (HMSO 1990). The dimension of naked flagellates was multiplied by a factor 1.1 to compensate for shrinkage due to fixation (Choi \& Stoecker 1989). Phytoplankton cell volume (for diatoms, the volume of the vacuole was subtracted from the cell volume) was converted to carbon biomass using conversion factors: $0.22 \mathrm{pg}$ and 0.25 py $C_{\text {jini }}^{-3}$ were uscd for prokaryotic and cukary otic picoplankton, respectively (Søndergaard et al. 1991), $0.13 \mathrm{pg} \mathrm{C} \mu \mathrm{m}^{-3}$ was used for thecate dinoflagellates, and $0.11 \mathrm{pg} \mathrm{C} \mu \mathrm{m}^{-3}$ for all other phytoplankton cells (Mullin et al. 1966, BMEPC-HC 1988).

Data treatment. The CHEMTAX program (Mackey et al. 1996) was used for calculating the biomass as chl $a$ of the phytoplankton groups in the 4 different experiments, using the pigment/chl a ratios derived from the laboratory experiments. All detected diagnostic pigments as well as pigments that are not unambiguous markers, but indicative of the presence of only a few algal groups (e.g. chl b, lutein, violaxanthin, neoxanthin, fucoxanthin, zeaxanthin) were included in the files, while the 2 light-protecting pigments, diadinoxanthin and diatoxanthin (Demers et al. 1991), $\beta, \beta-$ carotene, $\beta, \varepsilon$-carotene and chl $c$ were not included, as recommended by Mackey et al. (1996). Pedinellophytes, originally included in the class Chrysophyceae sensu Christensen (1962), but later defined as the class Pedinellophyceae (Melkonian 1989, Kristiansen 1990), were detected sporadically under the microscope, but were not included in the CHEMTAX program.

The pigment data from the Oosterschelde were divided into 3 data sets according to the average light intensities that reached the incubated water samples (Table 1): LL: 11 to $50 \mu \mathrm{mol}$ photons $\mathrm{m}^{2} \mathrm{~s}^{-1}$; ML: 51 to $150 \mu \mathrm{mol}$ photons $\mathrm{m}^{-2} \mathrm{~s}^{-1}$; HL: 151 to $429 \mu \mathrm{mol}$ photons $\mathrm{m}^{-2} \mathrm{~s}^{-1}$. The initial samples collected at the surface were accordingly placed in the HL group, and the 3 data sets were run separately in CHEMTAX with ratio files constructed from the light experiments (see 'Results'). The number of samples in LL, ML, and $\mathrm{HL}$ were 21,21 , and 27 , respectively. The data set as a whole was also run in CHEMTAX, using the average of the ratios of the 3 light intensities.

For the Hylsfjord data set, the average ratios of the 3 light intensities were used for constructing the CHEMTAX ratio file for the pooled water samples.

For the Great Belt and Oresund data sets, where the samples were collected in the surface waters or $0.5 \mathrm{~m}$ above $1 / 2$ Secchi depth, which both corresponded to high light intensity, the CHEMTAX program was loaded with pigment ratios for algae cultured in HL. In addition, the chl a biomass of the individual phytoplankton groups was calculated by CHEMTAX for all light treatments with the Great Belt data set to determine the influence of the different light treatments on the resulting chl a biomass.

\section{RESULTS}

\section{Laboratory experiments}

The pigmentichl a ratios for the different species grown in different light climates are shown in Table 2. $\beta, \beta$-carotene, $\beta$, $\varepsilon$-carotene and related carotenes were grouped as carotenes. $\mathrm{Chl} c_{1}$ and $\mathrm{chl} c_{2}$ were not separated by the HPLC method, and are named chl $c$ in Table 2. 
The diagnostic pigment/chl a ratios in dinoflagellates (peridinin), diatoms (fucoxanthin), the prymnesiophyte without 19'-hex, Isochrysis galbana (fucoxanthin), the pedinellophyte (fucoxanthin), one of the cryptophytes (Plagioselmis prolonga; alloxanthin), the chlorophytes (chl $b$ ), the prasinophytes (chl $b$ and/or prasinoxanthin), and the euglenophyte (siphonein/chl b) showed only minor variations at the different light intensities (Table 2). By contrast, in the prymnesiophytes containing $19^{\prime}$-hex and/or 19'-but, the pelagophyte (19'-but), the cryptophyte Rhodomonas salina (alloxanthin), and in the cyanobacterium (zeaxanthin), the diagnostic pigment/chl a ratios increased by at least $100 \%$ from LL to HL.

Among the non-diagnostic pigments, the ratios of diadinoxanthin, diatoxanthin, and carotene to chl a were strongly influenced by light intensity and generally increased with light intensity. The same response was seen for ratios of zeaxanthin and lutein to $\mathrm{chl} a_{\text {, }}$ present in many of the chlorophytes, prasinophytes, and euglenophytes, while the ratios of violaxanthin to chl a responded differently to light intensity in these algae (Table 2).

The influence of light quality on pigment/chl a ratios was not as profound as the effect of the light intensity, and the ratios in algae grown in GL and BL were generally within the range of the ratios of the 3 light intensities, LI, ML, and HL (Table 2). Exceptions were the 2 prymnesiophytes Emiliania huxleyi and Phaeocystis sp., which especially in BL for most pigments deviated from the ratios in light of different intensities, with higher $19^{\prime}$-hex/chl a ratios and lower fucoxanthin/chl a ratios (Table 2 ).

The pigment/chl a ratios in the SG cultures were generally within the range of the ratios of the 3 light intensities, although there were some exceptions. For example in the diatom Ditylum brightwellii, the fucoxanthin/chl a-ratio more than doubled in stationary phase compared to all other treatments (Table 2). In the prymnesiophytes Phaeocystis $\mathrm{sp}$. and Isochrysis galbana, the fucoxanthin/chl a ratio in stationary phase was lower than the average ratio found in all light intensities, while the fucoxanthin/chl a ratio in Emilinia huxleyi in SG was within the range of the light intensity treatments. The 19'-hex/chl a ratios were, however, higher for both Phaeocystis sp. and Emiliania huxleyi in SG compared to the light intensity treatments (Table 2). In the chlorophytes, prasinophytes and euglenophytes, the pigment/chl a ratios during SG were for some pigments occasionally slightly beyond the range found in the light intensity studies, although the prasinoxanthin/chl a ratio in SG in Pycnococcus provasolii deviated by being almost double the average ratio found in the light intensity treatments (Table 2).

\section{Field experiments}

In samples from the Oosteschelde, fucoxanthin was the dominant accessory pigment indicating dominance by diatoms (Fig. 1), and microscopy showed that several diatom species were dominant. At the beginning of the experimental period, however, 19'-hex was also detected, and single cells of various species of prymnesiophytes, as well as the colony-forming Phaeocystis sp., were observed under the microscope (Fig. 1). 19'but was not detected, indicating that it did not occur in
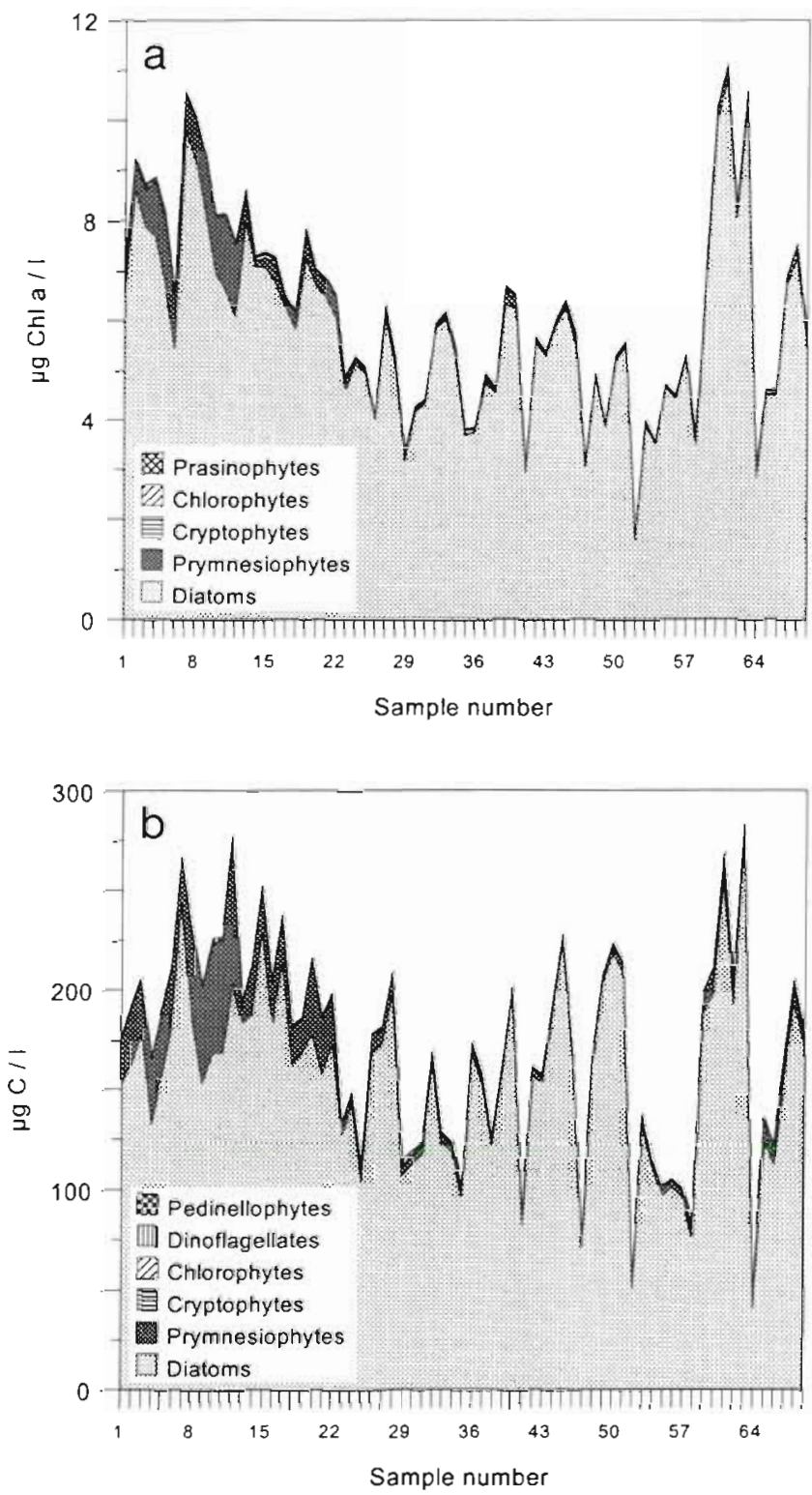

Fig. 1. Biomass of the phytoplankton groups in Oosterschelde, June 1996, determined by (a) phytoplankton pigments in chl a by CHEMTAX and (b) the carbon biomass estimated by microscopy. Numbers on the $x$-axis refer to the sample numbers 

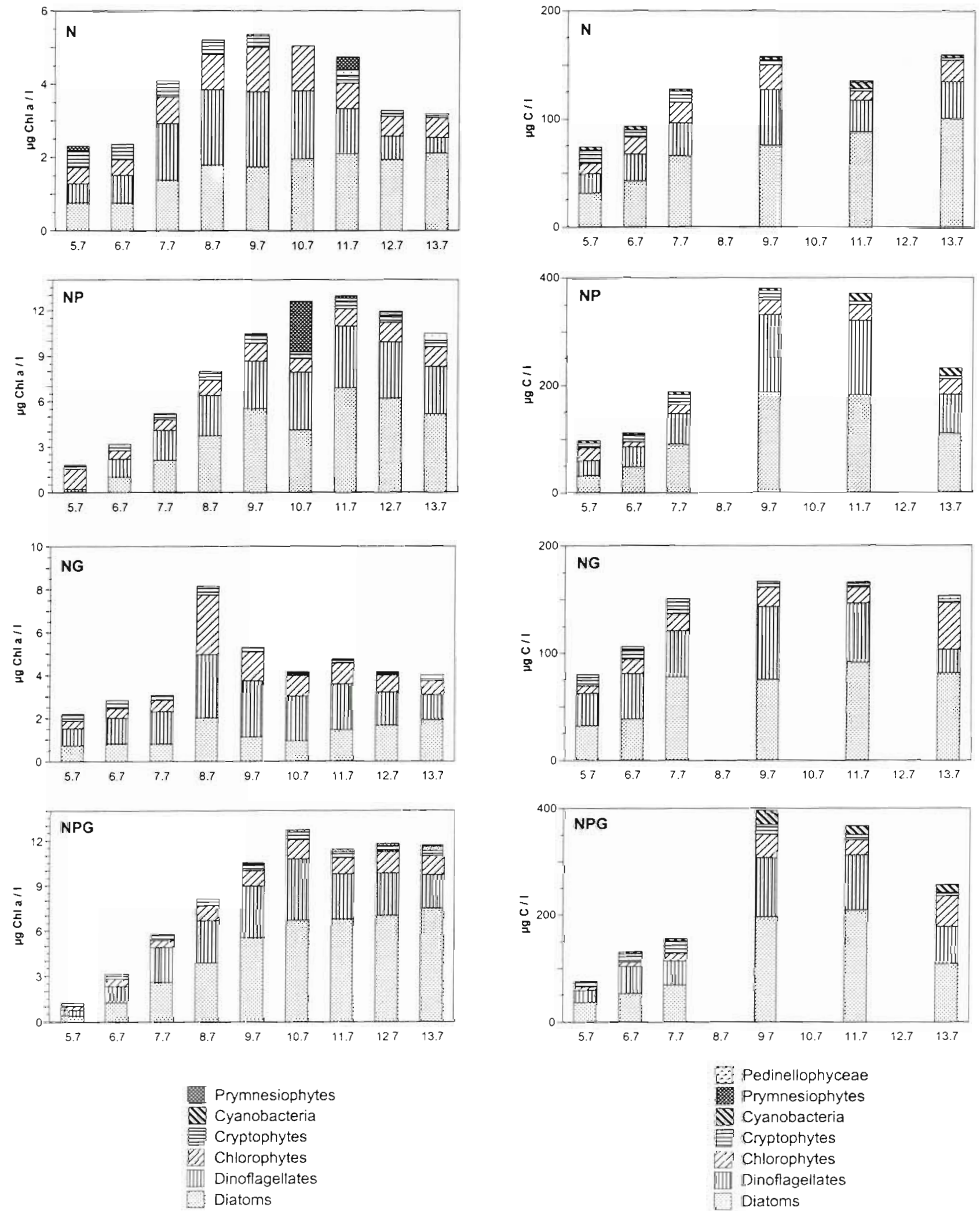

Fig. 2. Biomass of the phytoplankton groups in differently manipulated enclosures in the Hylsfjord from 5 to $13 \mathrm{July} 1995$ determined by phytoplankton pigments as chl a by CHEMTAX (left) and determined by microscopy as carbon biomass (right? N: nitrogen, NP: nitrogen and phosphorus, NG: nitrogen and glycine, NPG: nitrogen, phosphorus and glycine 
this Phaeocystis sp. (cf. Jeffrey \& Wright 1994). Alloxanthin, prasinoxanthin and chl $b$ (as well as lutein, neoxanthin, violaxanthin, diadinoxanthin, etc.; i.e. pigments which are not unambiguous markers) were found in small amounts, indicating low levels of cryptophytes, prasinophytes, and possibly also chlorophytes. Prasinophytes were not observed under the microscope; instead a few chlorophytes, dinoflagellates and pedinellophytes were detected, but the abundance of these algal groups was much lower than that of diatoms (Fig. 1).

The biomass as chl a of the phytoplankton groups determined by CHEMTAX for different light intensities agreed well with the carbon biomass estimated from the microscopic measurements (Fig. 1). Using the average pigment ratio of the 3 light intensities for the whole data set, instead of different pigment ratios for the different light intensities, did not, except for the prymnesiophytes, influence this result. The correlation between the carbon biomass and the biomass as chl $a$ calculated either using different ratios corresponding to the light intensities during the incubations or the average of the LL, ML and HL ratios were almost equal for the diatoms $\left(r^{2}=0.56\right.$ and 0.53 , respectively), and equal for cryptophytes $\left(\mathrm{r}^{2}=0.06\right.$ and 0.06 , respectively), and for chlorophytes $\left(r^{2}=0.07\right.$ and 0.07 , respectively). The chl a biomass of the prymnesiophytes, however, was affected by the pigment/chl a ratios chosen for the CHEMTAX program: $r^{2}$ was respectively 0.50 and 0.83 for the biomasses calculated by the different ratios corresponding to the light intensities during the incubation or the average pigment ratios.

The systematic repetition of valleys and peaks in Fig. 1 reflects the initial samples followed by samples that were incubated for 24 h at 5 different depths. During the incubation, the increase in carbon biomass was more pronounced than the increase in chl a, giving rise to significantly different carbon/chl a ratios before and after incubation: 25 and 29, respectively ( $t$-test, $p<0.05$ ). There was no significant difference in the carbon/chl a ratios for samples incubated at the 5 different depths.

In the Hylsfjord, microscopic analysis showed that diatoms and dinoflagellates were dominant, while chlorophytes, cryptophytes, cyanobacteria, prymnesiophytes, and pedinellophytes were present in lower concentrations (Fig. 2). The diagnostic pigments detected by HPLC were fucoxanthin, peridinin, chl $b$, alloxanthin and zeaxanthin, while the diagnostic pigment for Type 3 and Type 4 prymnesiophytes, $19^{\prime}$-hex (Jeffrey \& Wright 1994), was not detected. Instead, the pigment/chl a ratios of Type 1 prymnesiophytes (i.e. Isochrysis galbana, Table 2), as well as pigment ratios of other detected phytoplankton groups, were used for calculating chl a biomass of the individual phytoplankton groups in CHEMTAX. The biomass of the phytoplankton groups calculated using CHEMTAX for the Hylsfjord enclosures corresponded well with the carbon biomass observed under the microscope (Fig. 2). Both methods were able to detect the increase in diatoms and dinoflagellates especially in response to phosphorus addition as compared to the enclosures with added nitrogen (Fig. 2). Glycine had no effect on the phytoplankton groups.

The results of the 2 microscopic examinations of the same samples from the Great Belt are shown in Fig. 3. As Laboratory a was using ordinary light microscope only, smaller flagellates could not be identified and are grouped as 'unknown flagellates' (Fig. 3). Laboratory $b$ was able to identify flagellates and pico algae (i.e. pico cyanobacteria). Laboratory $b$ found that cyanobacteria were very abundant, while Laboratory a detected a small amount of chain-forming cyanobacteria on one
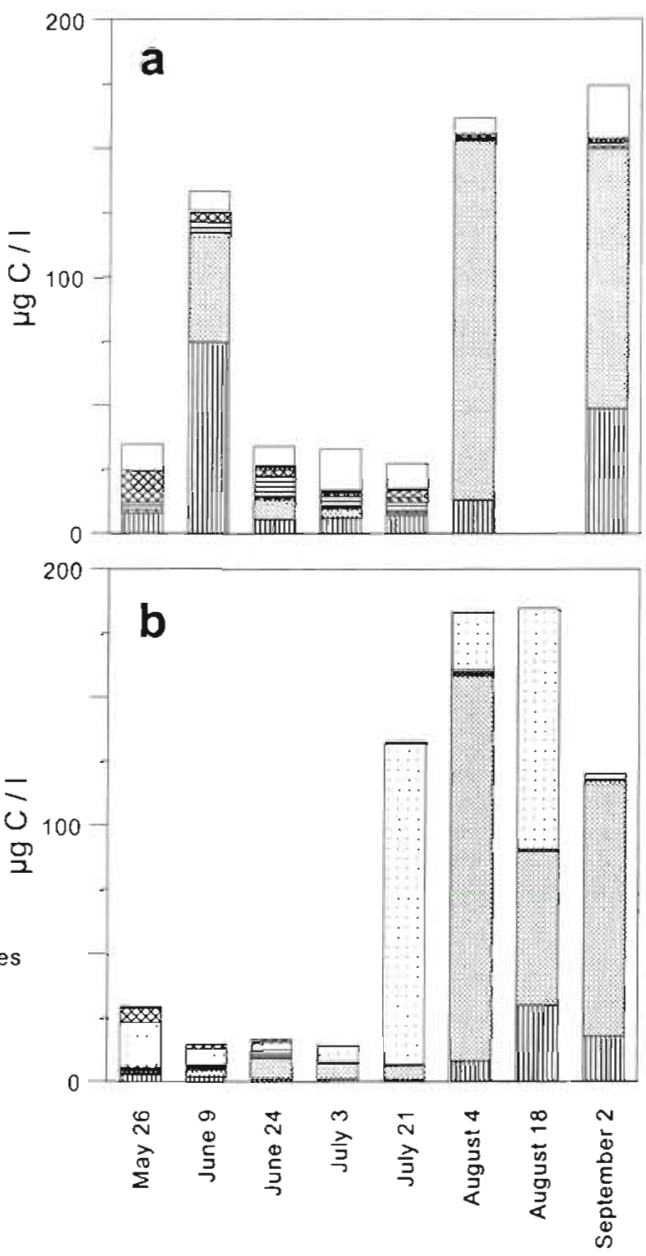

Fig. 3. Carbon biomass of the phytoplankton groups from the Great Belt, 1997, estimated by microscopy by 2 laboratories ( $a$ and $b$ ). (a) Laboratory a used only ordinary light microscopy, while (b) Laboratory $b$ used both ordinary light and epifluorescence microscopy 


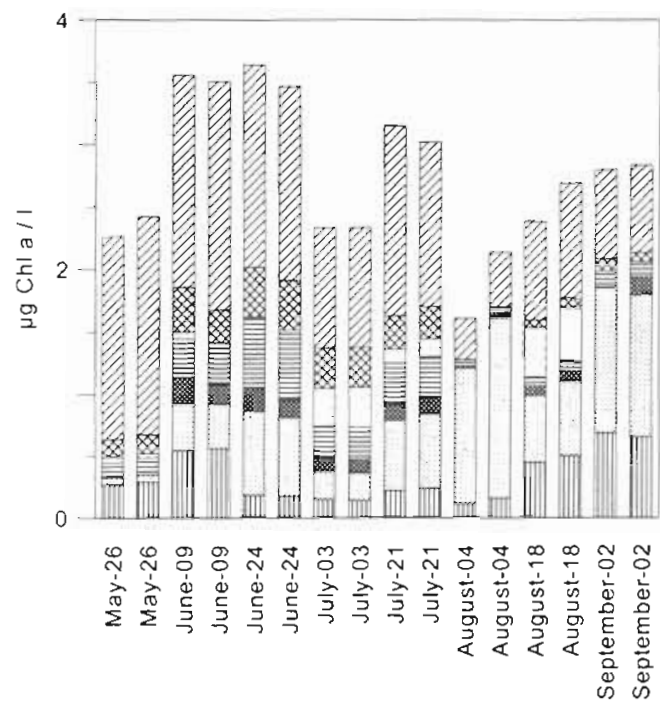

Fig. 4. Biomass of phytoplankton groups in the samples from the Great Belt, 1997, determined by phytoplankton pigments in chl a by CHEMTAX using ratios for algal cells in high light. Replicated samples on each date

day only (21 July). In the same sample, laboratory $b$ found cyanobacteria, especially Nodularia spumigena, to be dominant (Fig. 3). The 2 laboratories also disagreed on the total algal biomass on several dates, especially on 9 June, where the total carbon biomass estimated by Laboratory a was about 10 times higher than that found by Laboratory $b$, and on 21 July, where the biomass estimated by Laboratory a was more than 4 times lower than that found by Laboratory $b$. The 2 laboratories agreed that dinoflagellates and diatoms were the most abundant phytoplankton groups (excluding cyanobacteria) (Fig. 3), and both agreed that other groups, e.g. prasinophytes, cryptophytes, chrysophytes and prymnesiophytes, were sparse (Fig. 3).

The phytoplankton pigment composition found in the Great Belt was generally very diverse (Fig. 4) when represented as the phytoplankton biomass in terms of chl a calculated using CHEMTAX. There was good agreement between replicates (Fig. 4). Chlorophytes were always abundant, and diatoms and dinoflagellates were also prevalent (Fig. 4). Cyanobacteria, cryptophytes, prasinophytes, and prymnesiophytes were also present on all dates. The group composition and biomass detected with CHEMTAX, howcver, did not, except for dinoflagellates and diatoms, match the biomass determinations made by either laboratory (Fig. 4). All other groups, except cyanobacteria detected by Laboratory $a$, were generally more abundant when determined from pigment composition than from observations made from microscopy (Fig. 4).
Since many pigments were detected in considerable amounts in the Great Belt, this data set was used to test the influence of light and nutrients on the chl a biomass of individual phytoplankton groups by running the CHEMTAX program 6 times with the different pigment/chl a ratios for the different treatments (HL, ML, LL, GL, BL, and SG; Table 2). The chl a biomasses of prymnesiophytes and cyanobacteria calculated by CHEMTAX deviated from biomasses of chlorophytes, cryptophytes, prasinophytes, diatoms, and dinoflagellates by being significantly different in the different treatments $(p<0.05$ for prymnesiophytes and $p<0.001$ for cyanobacteria, single-factor ANOVA).

In Øresund samples, many different phytoplankton pigments were detected, indicating a diverse phytoplankton community. The biomass of prymnesiophytes, cryptophytes, diatoms, and dinoflagellates calculated using CHEMTAX was highest in the middle of the investigation area, while prasinophytes and chlorophytes generally decreased towards the dredger (Fig 5). The cyanobacteria showed a different distribution, with high biomasses at both ends of the investigation area (Fig. 5). A factor analysis confirmed the assumption that the phytoplankton groups were heterogeneously distributed in the investigation area (Fig. 6). There was generally good agreement between the samples taken at the surface and the samples taken $0.5 \mathrm{~m}$ above $1 / 2$ Secchi depth, and between pairs across the sediment plume (Fig. 5).

\section{DISCUSSION}

For the different treatments in the culture experiments, the light intensities in particular had an effect on the pigment/chl a ratios (Table 2), but the chl a biomass calculated for the individual phytoplankton groups by using CHEMTAX was only influenced significantly for cyanobacteria and prymnesiophytes with $19 '$-hex. It was expected that light would affect the biomass of cyanobacteria, since their diagnostic pigment, zeaxanthin, is involved in photo-protection (Bidigare et al. 1989) Previously, concentrations of photosynthetically active pigments were tound to co-vary with chl $a$ in diatoms, prymnesiophytes without 19'-hex. cryptophytes, chlorophytes, and prasinophytes under conditions of rhanging growth rates and irradiance. (Goericke \& Montoya 1998, and references herein), in agreement with the results of this study. An exception found in this study was prymnesiophytes with 19'-hex, which is a light-harvesting pigment. Vanleeuwe \& Stefels (1998) found this pigment to be the main carotenoid, at the cost of fucoxanthin, for iron-depleted 
$\mu \mathrm{gChlal}{ }^{-1}$

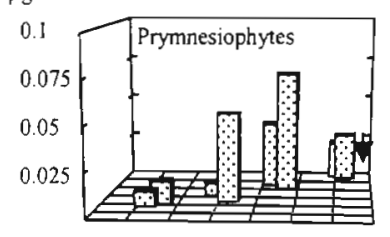

$$
\text { EW }
$$

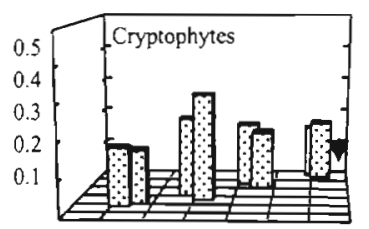

EW

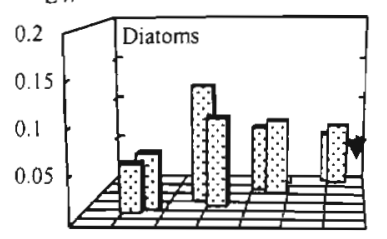

EW

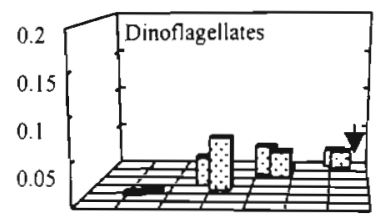

EW

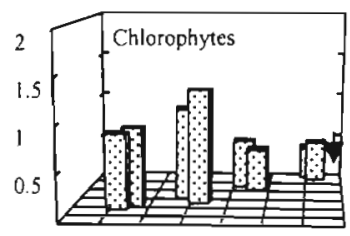

EW

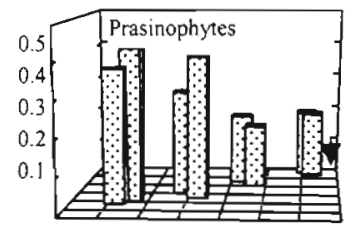

EW

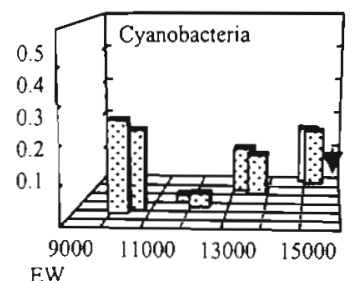

EW

Fig. 5. Spatial distribution of phytoplankton groups detected with pigments and subsequent analysis by CHEMTAX in Oresund, June 1997. The stations were distributed in pairs on both sides of a sediment plume that arose as a consequence of a spill by a dredger ( $\downarrow$ ). The left panels show samples taken in the surface, while the right panels show samples taken $0.5 \mathrm{~m}$ above $1 / 2$ Secchi depth.

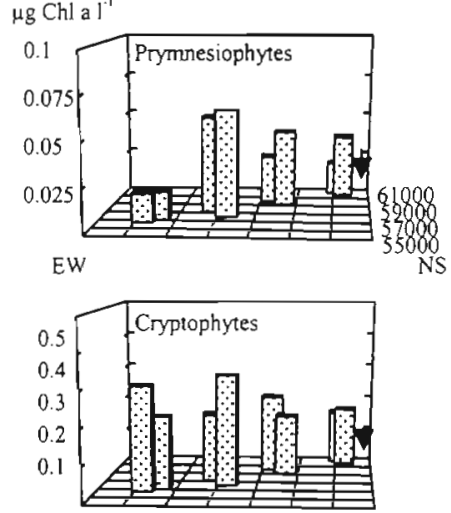

$\mathrm{EW}$

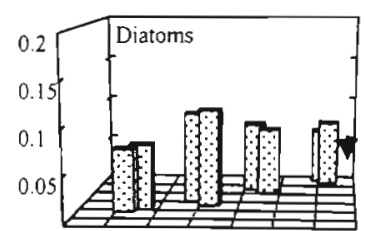

EW

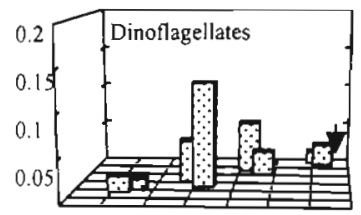

EW

NS

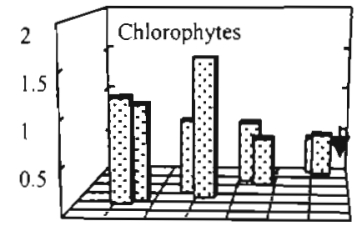

EW

NS

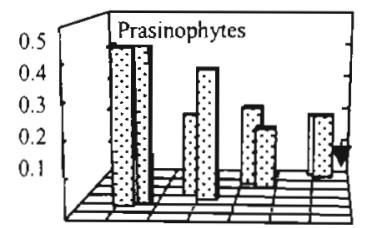

EW

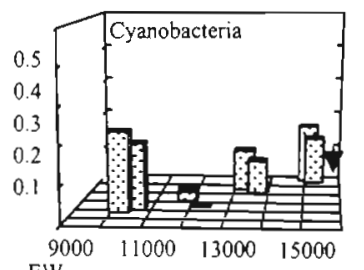

NS

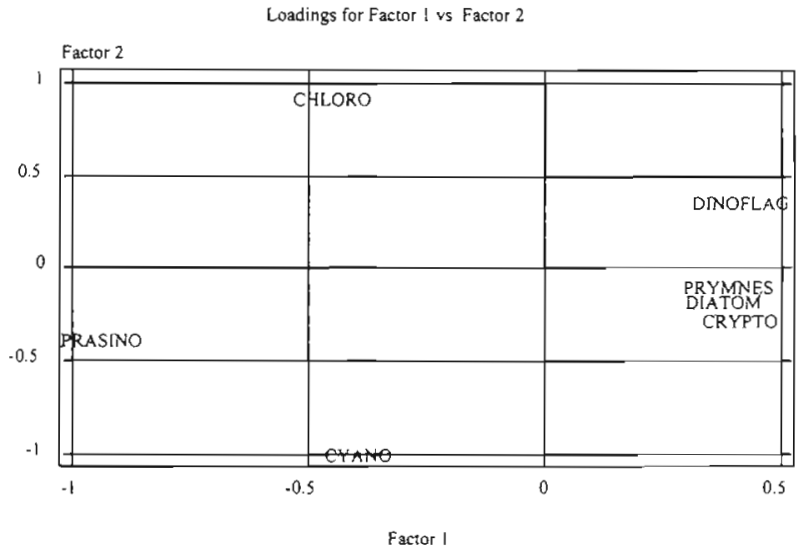

Fig. 6. A factor analysis of the samples from Oresund CHLORO: chlorophytes, PRASINO: prasinophytes, CYANO cyanobacteria, DINOFLAG: Dinoflagellates, PRYMNES: prymnesiophytes, DIATOM: diatoms, CRYPTO: cryptophytes

Phaeocystis sp. cells and speculated that hydroxylation of fucoxanthin (a highly efficient light-harvesting pigment) to $19^{\prime}$-hex and $19^{\prime}$-but may cause a modification of chloroplast membranes, which may result in a reduced efficiency of energy supply by the light-harvesting complex. This might explain the increase found in 19'-hex/chl a with increasing light intensity in this study, which was especially notable in SG (Table 2). 19'-but was not detected in field experiments, but ratios of $19^{\prime}$-but/chl a also changed with increases in light intensity and/or nutrient limitation (Table 2), indicating that the biomass of Type 4 prymnesiophytes and pelagophytes is also subject to considerable change depending on the ratios chosen for CHEMTAX determinations.

The values of pigment/chl a ratios in cultures grown under BL and GL were generally within the range of ratios found in cultures grown at various white light intensities (Table 2). Light intensity is apparently more important than the quality of light (i.e. prevalence of BL in oligotrophic areas or GL in coastal areas and estuaries) for CHEMTAX biomass calculations. Pigment/chl a ratios in the SG cultures were either below or above the range of pigment ratios seen in the different light intensity studies for some of the algal species (Table 2, e.g. Ditylum brightwellii, Emiliania huxleyi, Isochrysis galbana, Phaeocystis sp., Pycnococcus provasolii). In natural environments, remineralization of nutrients by heterotrophic organisms (which were not included in the culture studies) will always provide some supply of nutrients for the algae, since phytoplankton growth and grazing by heterotrophic organisms are closely coupled (Schlüter 1998). Nutrient deficiency is especially pronounced at the end of 


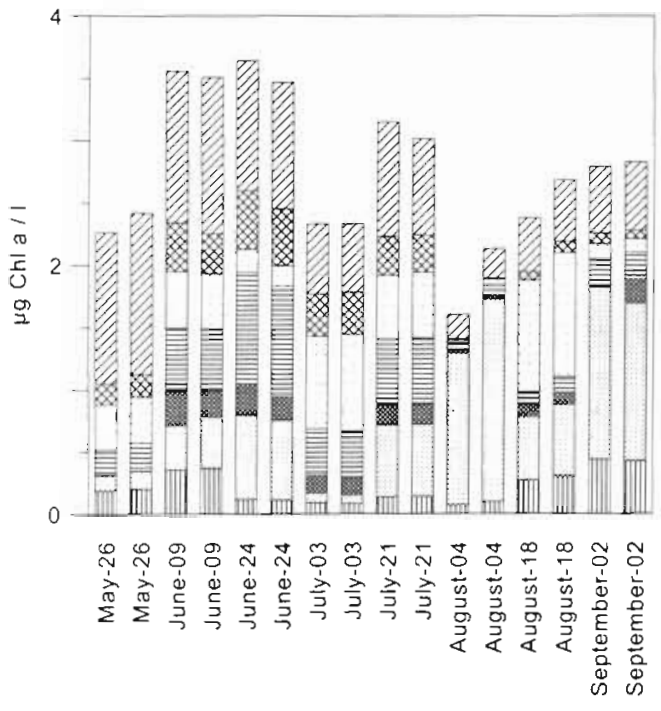

Fig. 7. Biomass of phytoplankton groups in samples from the Great Belt, 1997, determined by phytoplankton pigments in chlorophyll a by CHEMTAX using average light intensity ratios. Replicate samples for each date were determined

monospecific phytoplankton blooms; in multispecies phytoplankton communities, nutrient requirements of the individual species vary (Sakshaug \& Olsen 1986). The results of the SG cultures in this study therefore may not reflect in situ conditions and are probably most applicable to monospecific post-bloom situations.

When the pigment/chl a ratios for 2 species from the same group (e.g dinoflagellates, diatoms, cryptophytes, and chlorophytes; Table 2) were compared, inter-species variability in pigment/chl a ratios actually exceeded differences in the ratios caused by the different growth conditions. Mackey et al. (1996) suggested that pigment ratios to be used in CHEMTAX should come from the major phytoplankton species native to the area from which the samples were obtained. Cultures in this study were generally species prevalent in estuaries and coastal areas, but none of them were dominant in the samples according to microscopic enumeration. Thus, the average pigment/chl a ratios of the 2 species from the same group were used for constructing the CHEMTAX ratio files, as an approximation, although these might have caused even larger errors in the chl a biomass for these algae than the errors which might have arisen as a consequence of not considering the light climate.

The 4 field experiments were carried out in different coastal environments and sampling included temporal and spatial variations as well as differences in light and nutrients. The data sets were therefore suitable for testing the ratios derived from the laboratory experiments with the CHEMTAX program. chl a is the terminal photosynthetic pigment in light absorption, and the concentration of chl a is generally perceived as an index of the living, photosynthetically active phytoplankton biomass (Sakshaug et al. 1997). The carbon/chl a relation in the phytoplankton cells varies with changes in irradiance or nutrient limitation (e.g. Goericke \& Montoya 1998). In the Oosterschelde, for example, light intensities during the incubations at the 5 different depths (Table 1) were all relatively high, even in the samples which were at the bottom, and the carbon/chl a ratios did not differ appreciably. After the $24 \mathrm{~h}$ incubation, however, increases in carbon/chl a ratios were observed, probably owing to a reduction in nutrient concentrations. Phytoplankton carbon estimates from microscopic enumerations are generally quite variable, i.e. the coefficient of variation is between 15 and 50\% (Wilhelm et al. 1991). Comparing the chl a biomass of individual phytoplankton groups calculated by CHEMTAX to microscopic enumerations was therefore not optimal, but such a comparison was the only way to evaluate the results of the CHEMTAX program.

Pigment analyses by HPLC and subsequent data treatment by loading the pigment concentrations and the ratio file for the appropriate light climate into the CHEMTAX program, resulted in a successful description of both the composition of the phytoplankton groups and their respective biomass in the Oosterschelde and the Hylsfjord compared with biomass estimates made by microscopy (Figs. 1 \& 2). Even in the Hylsfjord, where the diagnostic pigment $19^{\prime}$-hex was not detected, the CHEMTAX program was able to satisfactorily calculate the abundance of prymnesiophytes without 19'-hex, using estimates of carbon biomass made from the microscope as a comparison (Fig 2). Similar results were obtained by Mackey et al. (1996, 1998) for Prochlorococcus sp., where CHEMTAX was able to estimate the abundance of Prochlorococcus sp., even though the concentrations of divinyl chls $a$ and $b$ were not measured. Pigments detected by HPLC are able to reveal phytoplankton groups which are difficult to detect and identify when algal cells are counted by microscopy (Wright et al. 1996), depending on the resolution of the microscope and the operator's skill. This was the case in the Oosterschelde, where prasinoxanthin was detected, even though prasinophytes were not identified under the microscope. Chlorophytes were identified, however, and CHEMTAX was able to quantify the contribution of both prasinophytes and chlorophytes, although their occurrence was rather sporadic compared to the diatoms (Fig. 1). Running the CHEMTAX program only on the basis of the diagnostic pigments detected, however, might cause the biomass of phytoplankton groups 
without diagnostic pigments (e.g. chrysophytes, dinoflagellates with prymnesiophyte endosymbionts instead of peridinin (Tangen \& Bjornland 1981), subtypes of prymnesiophytes lacking $19^{\prime}$-hex (Jeffrey \& Wright 1994), prasinophytes without prasinoxanthin (Egeland et al. 1995), to be included erroneously in the biomass of other groups. The optimal use of the pigment data is therefore achieved, if preserved sub-samples are examined under the microscope to identify groups without diagnostic pigments prior to analysis of HPLC results using CHEMTAX.

For the data set from the Great Belt, the results of the CHEMTAX program resembled neither of the biomass estimates made by the 2 laboratories on the basis of microscopic analyses (Figs. $3 \& 4$ ). Furthermore, the biomass estimates made by the 2 laboratories were not consistent, emphasizing the problem of subjectivity of microscopy of phytoplankton cell detection and cell measurements. A major cause of the severe discrepancies in the results from the 2 laboratories definitely arose from the use of an ordinary light microscope in Laboratory a, since many flagellates (up to $50 \%, 3$ July) could not be identified, and practically all nonchain-forming cyanobacteria, i.e. Synechococcus sp., were too small to be detected (Fig. 3). Although larger algae cells, e.g. dinoflagellates and diatoms, are common in coastal areas and estuaries, algal cells of smaller size are also present, particularly during periods of stratification and low nutrient concentrations (Havskum \& Riemann 1996). Using only light microscopy for biomass estimates of phytoplankton groups will not provide satisfactory results if smaller algal cells are prevalent.

Even though Laboratory $b$ used epifluorescence microscopy as well as ordinary light microscopy, their estimated carbon biomass and the CHEMTAX results were still not consistent. The abundant phytoplankton groups, i.e. cyanobacteria and diatoms in Fig. 3b, were more dominant than what was apparent from pigment analysis, indicating that less abundant species may have been overlooked. For example on 21 July, Laboratory $b$ found cyanobacteria to dominate completely. Although calculations made using CHEMTAX may be subject to error, practically all of the diagnostic pigments occurred in a relatively large amount according to HPLC analysis, indicating that the other phytoplankton groups were definitely significant contributors to the total chl a biomass. The chl a biomass of cyanobacteria (and prymnesiophytes) was significantly influenced by the ratios chosen for the CHEMTAX analysis. Thus, if the phytoplankton cells had become light-adapted to light intensities other than our experimental HL, for instance, during transport or handling in the laboratory, or if the phytoplankton populations were nutrient starved, this would have influenced the biomass estimates of, especially, cyanobacteria. If we had used the average ratio of the 3 light intensities instead of the HL ratios, the estimates of biomass of cyanobacteria would have increased at the expense of the chlorophytes especially (also containing zeaxanthin) (Fig. 7). The general picture of a diverse phytoplankton community on all dates, however, did not change, even when loading other ratios (including the ratios selected by Mackey et al. 1996, data not shown), indicating that the CHEMTAX method is quite robust and not heavily dependent on the pigment/chl a ratios used.

The good agreement between the biomass as chl $a$, found by CHEMTAX, and the carbon biomass estimated by microscopy in the Oosterschelde and in the Hylsfjord (compared with the result from the Great Belt), is likely due to the prevalence of diatoms and dinoflagellates in those areas. These generally large cells are easy to identify and quantify, and as long as sufficient cells are counted, thereby reducing the statistical variability, the microscopic estimate of these groups is apparently quite precise.

The data set from Øresund provided an example of a spatially variable distribution of phytoplankton populations. This data set was not counted under the microscope, but in light of the discrepancies of the 2 microscopic investigations in Fig. 3, such counting may not have revealed the variation in phytoplankton groups over the $5 \mathrm{~km}$ transect. HPLC analysis of pigment composition, because of high sensitivity and reproducibility, provided an appropriate method for revealing such variations

\section{CONCLUSIONS}

Light intensity had an important effect on pigment/chl a ratios in some phytoplankton groups and therefore should be taken into account when ratio files are constructed for application of the CHEMTAX program. Inter-species variations in pigment/chl a ratios, however, were also considerable, indicating that the ratios chosen for the CHEMTAX calculations should, if at all possible, reflect the dominant phytoplankton species present in the sample. More experiments with a large number of algal species should be conducted to reveal the extent of this inter-species variability. Overall, however, the CHEMTAX program appears to be a robust method for determining the abundance of phytoplankton groups, even if certain diagnostic pigments are absent. The high sensitivity and reproducibility of the pigment method also allow the detection of differences between phytoplankton populations, which might not be easily detectable using standard microscopic techniques. 
Acknowledgements. We thank M. D. Mackey for a copy of the CHEMTAX program. M. Allerup, J. Damgaard and J. Larsen are all greatly acknowledged for their technical assistance. This study was funded by Mast IIl contract (MAS3-CT960053-PHASE), The Danish Research Councils (Project: Danish Environment Monitoring of Coastal Waters [DECO]), and VKl. This is ELOISE publication no. 109.

\section{LITERATURE CITED}

Abaychi JK, Riley JP (1979) The determination of phytoplankton pigments by High-Performance Liquid Chromatography. Anal Chim Acta 107:1-11

Althuis IA, Gieskes WWC, Villerius L, Colijn F (1994) Interpretation of fluorometric chlorophyl registrations with algal pigment analysis along a ferry transect in the southern North Sea. Neth J Sea Res 33:37-46

Andersen RA, Bidigare RR, Keller MD, Latasa M (1996) A comparison of HPLC pigment signatures and electron microscopic observations for oligotrophic waters of the North Atlantic and Pacific Oceans. Deep-Sea Res 43: $517-537$

Aure J, Rey F (1992) Oceanographic conditions in the Sandsfjord system, Western Norway, after a bloom of the toxic prymnesiophyte Prymnesium parvum Carter in August 1990. Sarsia 76:247-254

Bianchi TS, Baskaran M, Delord J, Ravichandran M (1997) Carbon cycling in a shallow turbid estuary of Southeast Texas-the use of plant pigment biomarkers and water quality parameters. Estuaries 20:404-415

Bidigare RR (1991) Analysis of algal chlorophylls and carotenoids. In: Hurd DC, Spencer DW (eds) Marine particles: analysis and characterization. Geophysical Monograph, Vol 63. American Geophysical Union, Washington, D.C., p 119-123

Bidigare RR, Schofield O, Prézelin BB (1989) Influence of zeaxanthin on quantum yield of photosynthesis of Synechococcus clone WH7803 (DC2). Mar Ecol Prog Ser 56: $177-188$

Bidıgare RR, Marra J, Dickey TD, Ituriaga R, Baker KS, Smith RC, Pak H (1990) Evidence for phytoplankton succession and chromatic adaptation in the Sargasso Sea during spring 1985. Mar Ecol Prog Ser 60:113-122

BMEPC-HC (Baltic Marine Environmental Protection Commission-Helsinki Commission) (1988) Guidelines for the Baltic monitoring programme for the third stage, Part $D$, Biological determinants. Baltic Sea Environ Proc 27:1-161

Choi JW. Stoecker DK (1989) Effects of fixation on cell volume of marine planktonic protozoa. Appl Environ Microbiol 55 : $1761-1765$

Christensen T (1962) Botanik, Vol 2, Sytematisk Botanik, No. 2. Alger. Munksgaard, Kobenhavn (in Danish)

Demers S, Roy S, Gagnon R, Vignault C (1991) Rapid lightinduced changes in cell fluorescense and in xanthophyllcycle pigments of Alexandrium excavatum (Dinophyceae) and Thalassiosira pseudonana (Bacillariophyceae): a photoprotection mechanism. Mar Ecol Prog Ser 76:185-193

Egeland ES, Eikrem W, Throndsen J, Wilhelm C, Zapata M.

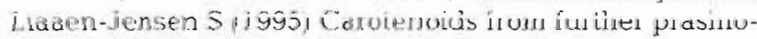
phytes. Biochem Syst Ecol 23:747-75.5

Everitt DA, Wright SW, Volkman JK, Thomas DP, Lindstrom EJ (1990) Phytoplankton community compositions in the western equatorial Pacific determined from chlorophyll and carotenoid pigment distributions. Deep-Sea Res 37: $975-9.97$

Gieskes WWC, Kraay GW (1983) Dominance of Crypto- phyceae during the phytoplankton spring bloom in the central North Sea detected by HPLC analysis of pigments. Mar Biol 75:179-185

Gieskes WWC, Kraay GW (1986) Floristic and physiological differences between the shallow and the deep nanophytoplankton community in the euphotic zone of the open tropical Atlantic revealed by HPLC analysis of pigments. Mar Biol 91:567-576

Gieskes WWC, Kraay GW, Nontji A, Setiapermana D, Sutomo (1988) Monsoonal alternation of a mixed and a layered structure in the phytoplankton of the euphotic zone of the Banda Sea (Indonesia): a mathematical analysis of algal pigment fingerprints. Neth J Sea Res 22:123-137

Goericke R, Montoya JP (1998) Estimating the contribution of microalgal taxa to chlorophyll $a$ in the field - variations of pigment ratios under nutrient- and light-limited growth. Mar Ecol Prog Ser 169:97-112

Havskum H, Hansen AS (1997) Importance of pigmented and colourless nano-sized protists as grazers on nanoplankton in a phosphate-depleted Norwegian fjord and in enclosures. Aquat Microb Ecol 12:139-151

Havskum H, Riemann B (1996) Ecological importance of bacterivorous pigmented flagellates (mixotrophs) in the Bay of Aarhus, Denmark. Mar Ecol Prog Ser 137:251-263

HMSO (Her Majesty's Stationary Office) (1990) The enumeration of algae, estimation of cell volume, and use in bioassays. Methods for the examination of waters and associated material. HMSO, London, p 1-44

Jeffrey SW, Wright SW (1994) Photosynthetic pigments in the Haptophyta. In: Green JC, Leadbeater BSC (eds) The haptophyte algae. Clarendon Press, Oxford, p 111-132

Jerlov NG (1968) Optical oceanography. Elsevier Publishing Company, Amsterdam

Keller MD, Selvin RC, Claus W, Guillard RRL (1987) Media for the culture of oceanic ultraphytoplankton. J Phycol 23 $633-638$

Kristiansen J (1990) Phylum Chrysophyta. In: Margulis L Corliss JO, Melkonian M, Chapman DJ (eds) Handbook of Protoctista. Jones \& Bartlett, Boston, p 438-453

Latasa M (1995) Pigment composition of Heterocapsa sp. and Thalassiosira weissflogii growing in batch cultures under different irradiances. Sci Mar 59:25-37

Letelier RM, Bidigare RR, Hebel DV, Ondrusek M, Winn CD, Karl DM (1993) Temporal variability of phytoplankton community structure based on pigment analysis. Limnol Oceanogr 38:1420-1437

Mackey MD, Mackey DJ, Higgins HW, Wright SW (1996) CHEMTAX - a program for estimating class abundances from chemical markers - application to HPLC measurements of phytoplankton. Mar Ecol Prog Ser 144:265-283

Mackey MD, Higgins HW, Mackey DJ, Holdsworth D (1998) Algal class abundances in the western equatorial Pacific. estimation from HPLC measurements of chloroplast pigments using CHEMTAX. Deep-Sea Res 45:1441-1468

Mantoura RFC, Llewellyn CA (1983) The rapid determination of algal chlorophyll and carotenoid pigments and their breakdown products in natural waters by reverse-phase high-performance liquid chromatography. Anal Chim Acta 151:297-314

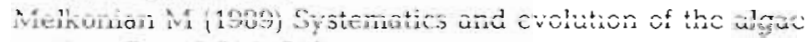
Prog Bot 50:214-245

Mullin MM, Sloan PR, Eppley PW (1966) Relationship between carbon content, cell volume, and area in phytoplankton. Limnol Oceanogr 11:307-311

Peeken I (1997) Photosynthetic pigment fingerprints as indicators of phytoplankton biomass and development in different water masses of the southern ocean during austral 
spring. Deep-Sea Res 44:261--282

Sakshaug E, Olsen Y (1986) Nutrient status of phytoplankton blooms in Norwegian waters and algal strategies for nutrient competition. Can J Fish Aquat Sci 43:389-396

Sakshaug E, Bricaud A, Dandonneau Y, Falkowski PG, Kiefer DA, Legendre L, Morel A, Parslow J, Takahashi M (1997) Parameters of photosynthesis-definitions, theory and interpretation of results. J Plankton Res 19:1637-1670

Schlüter L (1998) The influence of nutrient addition on growth rates of phytoplankton groups, and microzooplankton grazing rates in a mesocosmos experiment. J Exp Mar Biol Ecol 228:53-71

Schlüter L, Havskum H (1997) Phytoplankton pigments in relation to carbon content in phytoplankton communities. Mar Ecol Prog Ser 155:55-65

Søndergaard M, Jensen LM, Ertebjerg G (1991) Picoalgae in Danish coastal waters during summer stratification. Mar Ecol Prog Ser 79:139-149

Tangen K, Bjornland T (1981) Observations on pigments and morphology of Gyrodinium aureolum Hulburt, a marine dinoflagellate containing 19'-hexanoyloxyfucoxanthin as the main carotenoid. J Plankton Res 3:389-401

Thingstad TF, Skjoldal EF, Bohne RA (1993) Phosphorus cycling and algal-bacterial competition in Sandsfjord, western Norway. Mar Ecol Prog Ser 99:239-259

Editorial responsibility: Otto Kinne (Editor)

Oldendorf/Luhe, Germany
Thingstad TF, Havskum $H$, Kaas $H$, Nielsen TG. Riemann B Lefevre D, Williams PJleB (1999) Bacteria-protist interactions and organic matter degradation under P-limited conditions. Analysis of an enclosure experiment using a simple model. Limnol Oceanogr 44:236-253

Vanleeuwe MA, Stefels J (1998) Effects of iron and light stress on the biochemical composition of Antarctic Phaeocystis sp. (Prymnesiophyceae). ii. Pigment composition. J Phycol 34:496-503

Wilhelm C, Rudolph I, Renner W (1991) A quantitative method based on HPLC-aided pigment analysis to monitor structure and dynamics of the phytoplankton assemblages - a study from Lake Meerfelder Maar (Eifel, Germany). Arch Hydrobiol 123:21-35

Wright SW, Jeffrey SW, Mantoura RFC, Llewellyn CA, Biornland T, Repeta D, Welschmeyer N (1991) Improved HPLC method for the analysis of chlorophylls and carotenoids from marine phytoplankton. Mar Ecol Prog Ser 77: $183-196$

Wright SW, Thomas DP, Marchant HJ, Higgins HW, Mackey MD, Mackey DJ (1996) Analysis of phytoplankton of the Australian sector of the Southern Ocean-comparisons of microscopy and size frequency data with interpretations of pigment HPLC data using the CHEMTAX matrix factorisation program. Mar Ecol Prog Ser 144:285-298

Submitted: January 20,1999; Accepted: July 16, 1999 Proofs received from author(s): January 10, 2000 